\title{
Investigating Dimensions and Impairments Caused by Shifts in Nurses Who Work in Constant Shifts
}

\author{
Fereshteh Farzianpour ${ }^{1}$, Abbas Rahimi Foroushani ${ }^{2}$, Saeadeh Ansari Nosrati ${ }^{1}$, \\ Hamid Pourasghari ${ }^{3}$, Zahra Khakdel Jelodar ${ }^{1}$, Mohammad Bakhtiari1 \\ ${ }^{1}$ Department of Health Management and Economics, School of Public Health, Tehran University of Medical \\ Sciences, Tehran, Iran \\ ${ }^{2}$ Department of Epidemiology and Biostatistics, School of Public Health, Tehran University of Medical Sciences, \\ Tehran, Iran \\ ${ }^{3}$ Department of Health Services Management, School of Health Management and Information Sciences, Iran \\ University of Medical Sciences, Tehran, Iran \\ Email: farzianp@sina.tums.ac.ir, ${ }^{*}$ farzianp2@yahoo.com, rahimifo@tums.ac.ir
}

Received 14 April 2015; accepted 5 June 2015; published 8 June 2015

Copyright (C) 2015 by authors and Scientific Research Publishing Inc.

This work is licensed under the Creative Commons Attribution International License (CC BY).

http://creativecommons.org/licenses/by/4.0/

(c) (7) Open Access

\section{Abstract}

The purpose of this study was to investigate the dimensions and conditions caused by shifts in nurses who worked in constant shifts in non-governmental selective hospitals in Tehran in 2014. In this cross-sectional and applied research, the shifts standard questionnaire was used. After confirming the validity and reliability (Cronbach's alpha 0.73 ), the questionnaires were distributed among 305 nurses of 6 non-governmental selective hospitals in Tehran, based on stratified random sampling. In the research, the data analysis was conducted in two levels of descriptive and inferential statistics. The response rate was $0.91 .74 .4 \%$ of the participant nurses were female and $25.6 \%$ were male. The results showed that there was a significant relationship between age and physical health $(P=0.008)$, gender and physical health $(P=0.015)$, education and health $(P=0.014)$, gender and physical-cognitive anxiety $(P=0.006)$, age and social-familial status $(P=0.001)$, Marital status and social-familial status $(P=0.001)$, having a second job and social-familial status $(P=0.001)$, education and sleep-fatigue $(P=0.002)$. Planning with respect to standards of nurses' working hours and avoiding overtime, especially nurses who have more experience, can prevent severe complications of shifts and improve health level and ultimately the quality of care.

\footnotetext{
"Corresponding author.
}

How to cite this paper: Farzianpour, F., Foroushani, A.R., Nosrati, S.A., Pourasghari, H., Jelodar, Z.K. and Bakhtiari, M. (2015) Investigating Dimensions and Impairments Caused by Shifts in Nurses Who Work in Constant Shifts. Health, 7, 665-671. http://dx.doi.org/10.4236/health.2015.76079 


\section{Keywords}

\section{Shift, Impairments Related to Shift, Nurse}

\section{Introduction}

Nowadays, due to the progress of societies, population growth, industrialization of countries and requirements of some jobs, a considerable proportion of employees are working with shifts-scheduled programs [1]. In general, any work which is regularly and certainly done outside of the daily time-box, can be considered as shift. In other words, shift is defined as a non-standard and necessary program that at least $50 \%$ of its time consists of hours apart from 8 am to $4 \mathrm{pm}$ [2]. Today, shifts are considered as a cause of health problems which can have adverse effects on various aspects of human life [3].

So far, several studies have been conducted to evaluate the adverse effects of shifts on performance, health and quality of life of individuals who work with shift schedules. Some of these studies have shown the relationship between shifts and emergence of physical and psychological complications [4]. Shifts are more prevailed in large and complex working environments. Thus, in such environments, its adverse effects are considerably higher [2]. Combining shifts and multiple disruptions of workplace, high physical and cognitive needs, loss of individual's control over his work and other psychomotor and social stressors, would impose additional negative effects on the health of employees [5].

The groups of health care staff and in particular, nurses are groups that have to be shift-worker due to job requirements [1]. In our country, nurses make up 80 percent of workers in the health care system [6]. Nurses are at the forefront of providing health services to provide the needs of patients and are forced to work at all hours of the day [6]. Nurses irregularly work in morning, afternoon and evening shifts and are more prone to mental stresses in comparison to other professions [7]. The deleterious effects of shift work are mainly chronic. These effects include disruption of physiological processes such as sleep-wake cycle, undermining the physical and psychological health, problems of alertness, performance, safety and difficulties for family and social life.

Based on studies, the frequency of shifts in European countries is 15 to 20 percent and in America is 20 percent of the workforce [8]. This prevalence is a good reason for studying its negative effects on health, safety and efficiency of the staff. The Biological rhythms are greatly impaired due to night shifts [9]. In addition, they lead to disruption of family and social life that has a negative effect on performance and social relationships. These undesirable aspects cause acute and chronic effects. These effects not only increase the number of events but also appear as sleep disorders, excessive sleepiness during the day and mental and physical disorders [10].

The impact of shift work on people is mainly related to individual's job, personal characteristics, social and organizational environment and properties of the shift schedule. According to cited matters, it can be stated that working with shifts-scheduled program for long time can cause adverse and chronic physical, physiological and psychological effects in shift workers [11]. Hanhart and colleagues showed that those who worked in 2 and 3 times shifts, significantly had greater sleepiness than constant morning or the evening workers. Apart from shift schedules, the greatest risks of sleep disturbance were related to age, less leisure time and the use of sedative drugs [12].

Protla and colleagues showed that Migraine attacks and the need for medical services are more prevailed in day workers than night workers. Reported mild mental disorders such as depression, anxiety, stress and insomnia was lower in evening and night workers compared to day workers [13]. Since the shift work is a necessity in the field of medical services and common problems associated with it affect the quality of health care workers and health and satisfaction of patients, preventing and mitigating them seem necessary [14]. Therefore, the present study has been conducted among nurses in non-public hospitals in Tehran to determine the adverse dimensions of the problems of shifts and its association with demographic factors.

\section{Methods}

This cross-sectional study has been conducted in 2014. The samples number was determined 305 with confidence of 0.95 and the test power of 0.90 and by the 2-stage cluster sampling method. The research environment consisted of 6 non-governmental hospitals in Tehran which were randomly selected. In the study, the inclusion 
criteria for the nurses was that they work in each constant work group at least for a year and taking into account this fact that factors such as a history of sleep disorders, asthma, diabetes, coronary artery disease, mental disorders, epilepsy, history of gastrointestinal disorders, history of alcohol and drug use, in compliance with the phenomenon of shift work, make problem and are of disruptive variables. So people with these disorders were excluded.

The data collection tool in this study was the Shifts Standard Index Questionnaire of Scientific Committee of the International Congress of Night Work and Shift Work of Occupational Health in 2008. The validity was confirmed by a group of experts in the management of health services and occupational health. After confirming the validity and reliability (Cronbach's alpha 0.73) the questionnaires were distributed among 305 nurses of 6 non-governmental selective hospitals in Tehran, based on stratified random sampling. In the research, the data analysis was conducted in two levels of descriptive and inferential statistics. The response rate was 0.91 .

The Shifts Standard Questionnaire consisted of 67 questions and has been codified in 5 sections that included demographic characteristics, sleep and fatigue, physical health, cognitive-physical anxiety and family-social status (adverse impacts on individual activities such as resting, reading, exercising, going to the lab, go to the bank).

The data collected in this study was analyzed using the software SPSS 22. To assess the relationship between variables, the Pearson's correlation coefficient, the Paired t-test, ANOVA analysis, Mann-Whitney test, and the Kruskal-Wallis test were used.

\section{Findings}

$25.6 \%$ of the subjects were male and $74.4 \%$ were female. $43.6 \%$ were single and $56.4 \%$ were married. $10.5 \%$ of people had a diploma or associate's degree, $81 \%$ of people had bachelor's degree and $8.5 \%$ had a master's degree. $76.4 \%$ did mandatory overtime and $23.6 \%$ did voluntary overtime (Table 1 ).

Table 1. Demographic characteristics of the study population.

\begin{tabular}{|c|c|}
\hline \multicolumn{2}{|c|}{ Variable percentage } \\
\hline \multicolumn{2}{|l|}{ Gender } \\
\hline male & 25.6 \\
\hline Female & 74.4 \\
\hline Age 21 - 29 years & 26.6 \\
\hline 30 - 39 years & 50.5 \\
\hline More than 40 years & 23 \\
\hline \multicolumn{2}{|l|}{ marital status } \\
\hline single & 43.6 \\
\hline Married & 56.4 \\
\hline \multicolumn{2}{|l|}{ Work experience } \\
\hline lower than 5 years & 28.9 \\
\hline 5 - 10 years & 33.1 \\
\hline Over than 10 years & 38 \\
\hline \multicolumn{2}{|l|}{ Educational level } \\
\hline diploma and associate's degree & 10.5 \\
\hline Bachelor’s degree & 81 \\
\hline MA degree & 8.5 \\
\hline \multicolumn{2}{|l|}{ Employment status } \\
\hline contractual or plan-based & 66.9 \\
\hline Contractual & 18.7 \\
\hline Formal & 14.4 \\
\hline \multicolumn{2}{|l|}{ Shifts } \\
\hline constant morning & 27.2 \\
\hline constant afternoon & 28.5 \\
\hline constant evening & 44.3 \\
\hline \multicolumn{2}{|l|}{ Work overtime } \\
\hline volunteer overtime & 76.4 \\
\hline mandatory & 23.6 \\
\hline \multicolumn{2}{|l|}{ second job } \\
\hline Yes & 31.3 \\
\hline No & 68.8 \\
\hline
\end{tabular}


The average sleep and fatigue was 38.52\% among the nurses participating in the study. The average of family and social activities was $23.37 \%$. The highest average was related to sleep and fatigue. Due to negative being of these questions, this average shows the irrelevant situation in this regard (Table 2).

Using the Spearman correlation test, there was a correlation between age and physical health $(\mathrm{P}<0.05)$. Using the Mann-Whitney, the relationship between gender and physical health were significant $(\mathrm{P}<0.05)$. As a result, the physical health status in women was worse than men. Using the Kruskal-Wallis statistical test, the relationship between education and health well-being was significant $(\mathrm{P}<0.05)$. Using the Mann-Whitney, the relationship between gender and cognitive-physical anxiety was significant $(\mathrm{P}<0.05)$. As a result, the cognitive-physical anxiety in women was worse than men. Based on the Spearman correlation test, there was correlation between age and family-social status $(\mathrm{P}<0.001)$. As a result, as much as age increases the family and social situation becomes better. Using the Mann-Whitney, the relation between marital status and family-social status was significant $(\mathrm{P}<0.001)$. As a result, the social-family status of married nurses were better than unmarried nurses. Also using the Mann-Whitney Test, the relationship between the second job and family-social status was significant $(\mathrm{P}<0.001)$.

As a result, social-family status of the nurses who didn't have second jobs was better than nurses who had a second job. Using the one-way ANOVA analysis, there was a significant relationship among sleep and fatigue and education $(\mathrm{P}<0.05)$. According to findings of the Scheffe post-hoc test, the mean score of sleep and fatigue, there was a significant difference between the two groups with a Diploma and Advanced Diploma degree and Bachelor's degree $(\mathrm{P}<0.001)$ and two groups with a Diploma and Advanced Diploma degree and Master's degree $(\mathrm{P}<0.001)$ Table 3.

\section{Discussion}

Health care services are the services that many people, such as nurses, are engaged with them in different shifts and as shifts works. Many practitioners in this profession don't have the ability to adapt to shifts and are faced with problems [15]. Therefore, the importance of this issue and prevention of disruptions in the future provided the motivation for this study that by conducting a research, the problems and difficulties arising from shifts for nurses be investigated. The results showed that working in shift scheduled systems can be problematic for individuals' life condition from different angles, such as social and health problems including digestive disorders and insomnia [16].

Table 2. Average of shifts dimensions for studied nurses.

\begin{tabular}{cccccc}
\hline Scope & Min & Max & Total & Mean & SD \\
\hline Health and well being & 16 & 51 & 9461 & 31.12 & 7.105 \\
Tiredness and fatigue & 27 & 51 & 11,672 & 38.52 & 4.585 \\
Cognitive-physical anxiety & 14 & 39 & 7077 & 23.28 & 5.522 \\
Family-social activities & 12 & 40 & 7084 & 23.37 & 5.153 \\
\hline
\end{tabular}

Table 3. Results of analysis tests.

\begin{tabular}{|c|c|c|c|}
\hline Correlation coefficient & Relationship between physical health status and gender & $P=0.008$ & $\begin{array}{c}N=304 \\
Z=0.152\end{array}$ \\
\hline Mann-Whitney & Relationship between physical health status and gender & $\mathrm{P}<0.05$ & $Z=2.431$ \\
\hline Kruskal-Wallis & Relationship between physical health status and education & $\mathrm{P}<0.05$ & $X^{2}=8.568$ \\
\hline Mann-Whitney & Relationship between gender and cognitive-physical anxiety & $\mathrm{P}<0.05$ & $Z=2.749$ \\
\hline Pearson Correlation & Relationship between age and family-social status & $P=0.001$ & $\mathrm{Z}=0.256$ \\
\hline Mann-Whitney & Relationship between social-family status of married nurses & $\mathrm{P}=0.001$ & $Z=6.269$ \\
\hline Mann-Whitney & Relationship between job and family-social status & $P=0.001$ & $Z=3.278$ \\
\hline one-way ANOVA & Relationship among sleep and fatigue and education & $\mathrm{P}<0.05$ & $\mathrm{~F}=6.33$ \\
\hline
\end{tabular}


In a study that was conducted in 2009 by Schoril et al. it was found that shifts increase stress and metabolic and peptic disorders [17]. In a study conducted in 2008 by Ohido et al. it was revealed that there is a significant association between working in night shift and drinking to help sleep induce [18]. In a study conducted in 2013 by Asghari et al. it was found that the highest incidence of problems was derived from shifts, were related to disruption of family, individual and societal lives for shift workers (<90\%) [18].

There was a significant correlation between age and physical health. The study by Imani and colleagues (2010) is consistent with our results. The results showed that the public health scores in young nursing students are higher. Nurses due to long work shifts and fatigue caused by this, are always prone to health threats in different dimensions and certainly not good public health nurses; will not be able to properly provide cares such as physical and psychological supports for patients that this issue raises the risk of errors and occupational accidents which finally, its outcomes is referred to the patient and nurse [19].

In this study, there was a significant relationship between gender and physical health. The Bazazian'sstudy (2009) was consistent with our results. The results showed that the public health scores in men are higher than women. Work in different shifts, especially night work, can jeopardize the wellbeing of women nurses who have family responsibilities such as pregnancy and child breeding [20]. Also, there was a significant correlation between the level of education and physical health. The study conducted by Hodjati et al. (2010) wasn't consistent with our study. The results of this study showed that with increasing experience of over 10 years, the physical health status improves. In the study conducted by Hodjati et al. the study group included the night shift nurses in public hospitals of Golestan University of Medical Sciences [21].

In our study, the nurses work in morning, afternoon and evening constant shifts in non-governmental hospitals in Tehran. Probably the difference in the samples led to discrepancy between two studies. In our study, no significant association was found between education and sleep and fatigue. The results of Chehri et al. (2006) were consistent with our results. The results showed there was a significant correlation between upper secondary education and no enough sleeping. Sleep disorder is the first and most common complaint associated with shifts in the world. The sleep disorder and sleepiness cause by this disruptions and loss of sleep cause that not only the individual be faced with mental and emotional disorders, but the working quality declines as well [22]. As the results showed a significant relationship between gender and physical-cognitive anxiety. The results of Zandi's study (2011) was consistent with our results. The results showed the female nurses were more anxious. Undoubtedly, the factors contributing to anxiety are widespread. Factors such as the level of skill, experience, selfesteem, ability to decision-making in times of crisis and the presence in emergency department are involved in anxiety creation. Some of the factors are adjustable and some others need to comprehensive protections to take effective steps for more efficiency in this career [23].

There was a correlation between age and family-social status. Also, there was a correlation between marital status and family-social status. The results of Sharifzadeh are consistent with our study. The results showed that there is a significant relationship between age and gender and work and family conflicts. The results of Sharifzadeh (2014) is consistent with our results. The results showed that there was a significant relationship between age and gender and work and family conflicts. Given the importance of job and family as the most important aspects of anybody's life, the need for coordination and integration between family needs and job requests seems necessary. Now the global increase in employed couples creates a challenge in most modern societies in terms of the balance between work and family affairs.

So that managing the responsibilities and family duties is described as one of the key problems in modern societies. This problem is due to the dramatic changes which have occurred in the nature of families and workplaces such as increased women's participation in workplaces and the creation of families in which both men and women work [24]-[29]. Individual differences and how individuals cope with the various work shifts, accuracy, and integrity, mental and emotional condition and studied subjects in response to questions, will affect the study's results that controlling them was outside the investigator's discretion. Since the concept related to shift work is very complex and conducting qualitative studies to identify the aspects of shift work in nurses seems necessary.

\section{Conclusions}

Planning in accordance with the standards of the nurses working hours and avoiding from overtime, in particular, for nurses who have more experience, can prevent occupational burnout and improve health level and ultimately 
the quality of care. On the other hand, with the promotion of the physical, psychological and social health of nurses, it can be expected that quality of patients' care improves as well.

Setting shifts schedule that is in accordance with biological cycles and environmental sciences will have a significant impact on reducing the problems caused by shifts.

- Informing managers about the impact and adverse effects of shifts on people who don't have the ability to adapt to shifts.

- Reducing the working hours of those working in the shift work system.

- Selecting individuals in shifts schedule system that have the ability to adapt to shifts.

\section{Acknowledgements}

Thereby all dears who helped us to conducting this research are appreciated.

\section{Competing Interests}

The authors declare that they have no competing interests.

\section{References}

[1] Mir Mohammad, J. (2010) The Effect of Shift Work on Depression among Nurses. Journal of Occupational Medicine, 27-24.

[2] Positive Practice Environments: Quality Workplace = Quality Patient Care. www.icn.ch/indkit2007.pdf

[3] Mardy, H., Zakerian, A., Jalali, M., Abaszadeh, M., Koruzhadeh, J. and Panjali, Z. (2014) Ergonomics Shift Work and Health Consequences Associated with It: A Case Study of the Security Staff of a Refinery Complex. Human Factors Engineering and Ergonomics Society's Journal, 2, 40-49.

[4] Mahmodi, H. and Sirati, M. (2010) The Study of Level of Stress in Head Nurses in Selected Tehran City Hospitals. College of Nursing and Midwifery, Tehran University of Medical Sciences, 21, 47-53.

[5] Mehrabi, T. and Ghazavi, Z. (2005) Survey Public Health of Woman Nurses in Hospitals of Isfahan University of Medical Science. Journal of Health, 1, 1-5.

[6] Suzuki, K., Ohida, T., Kaneita, Y., Yokoyama, E., Miyake, T., Harano, S., et al. (2004) Mental Health Status, Shift Work, and Occupational Accidents among Hospital Nurses in Japan. Journal of Occupational Health, 46, 448-454. http://dx.doi.org/10.1539/joh.46.448

[7] Potter, P. and Perry, G. (2007) Basic Nursing Theory and Practice. Publishing Salmi, Tehran, 815-820.

[8] Samaha, E., Lal, S., Samaha, N. and Wynahm, J. (2007) Psychological, Lifestyle and Coping Contributors to Chronic Fatigue in Shift-Worker Nurses. Journal of Advanced Nursing, 59, 221-232. http://dx.doi.org/10.1111/j.1365-2648.2007.04338.x

[9] Moonk, T. and Folkard, S. (2008) Shiftwork, Problems and Solutions. Shiraz University of Medical Sciences Publication, 3rd Edition, 1-4.

[10] Stoeber, J., Kempe, T. and Keogh, E.J. (2008) Facets of Self-Oriented and Socially Prescribed Perfectionism and Feelings of Pride, Shame, and Guilt Following Success and Failure.

[11] Bohle, P., Quinlan, M., Kennedy, D. and Williamson, A. (2004) Working Hours: Work-Life Conflict and Health in Precarious and "Permanent” Employment. Revista de Saúde Pública, 38, 19-25. http://dx.doi.org/10.1590/S0034-89102004000700004

[12] Hannhart, B., Adam, A., Courthiat, M.C., Leroux, C., Pale, S., Dousset, B., et al. (2006) Effects of Socio-Occupational Characteristics and of the Type of Rotating Shiftwork Schedule on Quality of Life and Sleep in Shift Workers. Epidemiology, 17, 513-521.

[13] Vanta, M. and Nobili, T. (2004) Sleepiness and Shift Work: Individual Differences. Journal of Sleep Research, 4, 5761.

[14] Anosheh, M., Ahmadi, F., Faghihzadeh, S. and Vaismoradi, M. (2007) Survey of Predisposing Causes of Working Errors in Nursing Cares from Perspective of Nurses and Their Managers Perspectives. Iran Journal of Nursing, 20, $25-$ 36. (In Persian)

[15] Plan Language about Shift Work—DHHS (NIOSH)—Publication No. 97, 145, 2005.

[16] Dong, X.W. (2005) Long Work Hours, Work Scheduling and Work Related Injuries among Construction Workers in the United States. Scandinavian Journal of Work, Environment \& Health, 31, 329-335. http://dx.doi.org/10.5271/sjweh.915 
[17] Esquirol, Y., Bongard, V., Mabile, L., Jonnier, B., Soulat, J.-M. and Perret, B. (2009) Shift Work and Metabolic Syndrome: Respective Impacts of Job Strain, Physical Activity, and Dietary Rhythms. Chronobiology International, 26, 544-559. http://dx.doi.org/10.1080/07420520902821176

[18] Ohida, T., Kamal, A., Sone, T., Ishi, T., Uchiyama, M., Minowa, A. and Nozaki, S. (2008) Night-Shift Work Related Problems in Young Female Nurses in Japan. Journal of Occupational Health, 43, 150-156.

[19] Soleimany, M., Nasiri Ziba, F., Kermani, A. and Hosseini, F. (2007) A Comparative Study of the General Health among Staff Nurses with Fixed or Rotating Working Shift. Iran Journal of Nursing, 20, 21-28. (In Persian)

[20] Bzazyan, S. and Bshart, M. (2010) Comparison of Emotional Intelligence, Psychological and Physical Health Careers. Journal of Applied Psychology, 3, 26-27. (In Persian)

[21] Hojaty, H., Jalalmanesh, S.H. and Fesharaki, M. (2010) Impact of Insomnia on General Health in Night Shift Nurses. Journal of Gorgan University of Medical Sciences, 11, 70-75. (In Persian)

[22] Ostovar, M. (2007) Shift Night Work and Risk Breast Cancer. Proceedings of the First National Conference on Occupational Hazards and Medicine Para Medicine, Dezfull, 264. (In Persian)

[23] Asad Zandi, M., Syary, R., Ebady, A. and Snayy, H. (2012) Depression, Anxiety and Stress in Military Nurses. Military Medicine Magazine, 13, 103-108. (In Persian)

[24] Sharifyzadah, F., Mohammadi, A., Alizadh, H., Pordanjani, S.K. and Heshmty, F. (2014) Relationship between Work-Family Conflict with Leaving Nurses. Iranian Journal of Nursing, 27, 23-33. (In Persian)

[25] Farzianpour, F., Vahidi, R.G.H., Foroushani, A.R., Arab, M. and Mohamadi, M. (2011) Investigating the Relationship between Organizational Social Capital and Service Quality in Teaching Hospitals. American Journal of Economics and Business Administration, 3, 425-429.

[26] Farzianpour, F., Foroushani, A.R., Beyzaiee, S. and Hosseini, S. (2012) Evaluation of the Self-Esteem Managers in Clinical Wards of Hospitals Affiliated to Tehran University of Medical Sciences. World Applied Sciences Journal, 16, 686-692.

[27] Farzianpour, F., Foroushani, A.R., Amerzadeh, M., Kor, E.M. and Hosseini, S.H. (2013) Evaluating Efficacy of Nursing Managers Using Performance Indicators of Patient and Staff Satisfaction. African Journal of Business Management, 7, 2043-2048. http://www.academicjournals.org/AJBM

[28] Farzianpour, F., Hamedani, A.T., Godarzi, L., Askari, R. and Hosseini, S.S. (2013) Evaluation of Customer Relationship Management in a Teaching Hospital. American Journal of Applied Sciences, 10, 344-352. http://www.thescipub.com/ajas.toc http://dx.doi.org/10.3844/ajassp.2013.344.352

[29] Farzianpour, F., Hosseini, S.M., Kor, E.M., Hosseini, S., Amerzadeh, M. and Ahmadi, B. (2013) The Relation between Nursing Administration's Self-Confidence and the Staff's Vocational Satisfaction. Iranian Journal of Public Health, 42, 410-416. http://ijph.tums.ac.ir 